\title{
Spectrum of Parotid Pathologies on Neck Ultrasound in A Tertiary Hospital of Western Nepal
}

\author{
Ghimire $\mathrm{P}^{1}$, Ghimire $\mathrm{PG}^{2}$, Poudel $\mathrm{N}^{3}$, Bhandari $\mathrm{S}^{4}$, Singh $\mathrm{BP}^{5}$
}

\begin{abstract}
Objective: To investigate the spectrum of parotid pathologies on neck ultrasound and correlation with pathological findings. Materials and methods: A total of 41 patients with parotid swelling who had undergone neck ultrasound were included in this prospective study. Patients with history of previous neck ultrasound, recent surgery, bleeding diathesis or trauma, equivocal pathological findings were excluded from the study between June 2016 to May 2018. On-site fine needle aspiration cytology was performed by a pathologist who was blinded to the ultrasound findings. Results: Among the 41 patients, $41.5 \%$ were males and $58.5 \%$ were females with age ranging from 1 to 76 years with a mean age of 37.31 years. Ultrasound was able to categorize lesions into benign and malignant with a sensitivity of $97.3 \%$, specificity of $50 \%$. Pleomorphic adenoma was the most common pathology ( $46.3 \%$ ) followed by inflammatory conditions. Mucoepidermoid carcinoma was the most common malignant tumor constituting $7.3 \%$ of the total cases. Conclusion:High resolution ultrasound can categorize parotid lesions with high degree of confidence in the hands of skilled radiologist. In equivocal cases, onsite fine needle aspiration by cytopathologist increases the diagnostic yield.
\end{abstract}

Key words: Mucoepidermoid carcinoma, parotid, pleomorphic adenoma

\section{INTRODUCTION}

Parotid swelling is a common presenting symptom of patients presenting to the Oto-rhinolaryngology department with varying etiologies posing clinical diagnostic dilemma. Parotid pathologies can range from inflammatory, infective, and benign to malignant cause ${ }^{1}$. High resolution ultrasound has played a key role in the identification of the lesions, perilesional important structures, characterization of the various pathologies thus avoiding inadvertent management. In our study, we reviewed the ultrasound characterized benign and malignant parotid pathologies and correlated with the pathological findings.

\section{MATERIALS AND METHODS}

A prospective study was conducted in the Department of Radiology at Nepalgunj Medical College and Teaching Hospital, Kohalpur, Banke for a period of two years from June 2016 to May 2018. All patients with parotid swelling who had presented to the radiology department for high resolution ultrasound scan were enrolled in the study that fulfilled all inclusion and exclusion criteria. All ultrasound scans were

1. Dr. Prasanna Ghimire

2. Dr. Pragya Gautam Ghimire

3. Dr. Nabin Poudel

4. Dr. Shama Bhandari

5. Prof. B. P. Singh

Address for correspondence:

Dr. Prasanna Ghimire

Department of Radiology

Nepalgunj Medical College \& Teaching Hospital

Kohalpur, Banke, Nepal

Email: drprasannaghimire@gmail.com performed on GE Logic P6 ultrasound machine with high frequency transducer (7.5-11 Mhz). With large lesions and for evaluation of the deep lobe pathologies, curvilinear lowfrequency transducers were used. Patients were placed in supine position with head tilted on opposite sides for evaluation of the parotid glands. Superficial, deep lobes of the gland as well as the Stenson's duct were assessed in crosssections. Lesions were noted for various parameters as size, location, margins, shape, echogenicity, echotexture and internal vascularity for characterizing the lesions as benign and malignant and when possibly suggest the possible diagnosis. Presence of accessory parotid glands was also noted. Regional lymph nodes were also scanned. Intraparotid lymph nodes which were oval in shape with short axis $<5 \mathrm{~mm}$, non-displaced, well preserved hyperechoic hilum were considered normal.

On site, FNAC of the lesion was performed by a single pathologist who had knowledge of only the location of the lesion and was blinded to the suggested radiological diagnosis. Pathological impressions with benign diagnosis were then correlated with the ultrasound findings.

Patients with history of previous neck ultrasound, recent surgery, bleeding diathesis or trauma, equivocal pathological findings were excluded from the study. All data were collected and statistical analysis was done in SPSS 16.0 (Chicago, Illinois).

\section{RESULTS}

A total of 41 cases fulfilled all the inclusion and exclusion criteria. The age of the patient ranged from 1 year to 76 years with a mean age of 37.3 years with a standard deviation of 14.85 years. Majority of the cases were in the $30-40$ years age group. There was female predilection with a female to male 


\begin{tabular}{|c|c|c|c|c|c|}
\hline SN & Age in years & Sex & Laterality & Ultrasound findings & Pathological diagnosis \\
\hline 1 & 34 & Male & Right & Acinic Cell Carcinoma & Pleomorphic Adenoma \\
\hline 2 & 36 & Female & Right & Pleomorphic Adenoma & Mucoepidermoid Carcinoma \\
\hline 3 & 36 & Male & Left & Acute Sialedenitis & Acute Sialedenitis \\
\hline 4 & 36 & Male & Right & Chronic Sialedenitis & Chronic Sialedenitis \\
\hline 5 & 13 & Male & Bilateral & Acute Sialedenitis & Acute Sialedenitis \\
\hline 6 & 76 & Female & Right & Benign Cystic Lesion & Benign Cystic Lesion \\
\hline 7 & 30 & Female & Right & Benign Cystic Lesion & Branchial Cleft Cyst \\
\hline 8 & 36 & Female & Left & Benign Cystic Lesion & Branchial Cleft Cyst \\
\hline 9 & 43 & Female & Right & $\begin{array}{c}\text { Carcinoma Ex Pleomorphic } \\
\text { Adenoma }\end{array}$ & $\begin{array}{c}\text { Carcinoma Ex Pleomorphic } \\
\text { Adenoma }\end{array}$ \\
\hline 10 & 52 & Female & Left & Chronic Sialedenitis & Chronic Sialedenitis \\
\hline 11 & 7 & Male & Right & Chronic Sialedenitis & Chronic Sialedenitis \\
\hline 12 & 45 & Female & Right & Benign Cystic Lesion & Lymphoepithelial Cyst \\
\hline 13 & 10 & Male & Right & Mucocele & Mucocele \\
\hline 14 & 57 & Male & Right & Mucocele & Mucocele \\
\hline 15 & 39 & Female & Left & Mucoepidermoid Carcinoma & Mucoepidermoid Carcinoma \\
\hline 16 & 46 & Male & Right & Pleomorphic Adenoma & Mucoepidermoid Carcinoma \\
\hline 17 & 37 & Female & Right & Parotid Abscess & Parotid Abscess \\
\hline 18 & 57 & Male & Right & Parotid Abscess & Parotid Abscess \\
\hline 19 & 19 & Male & Left & Parotid Lipoma & Parotid Lipoma \\
\hline 20 & 19 & Male & Right & Pleomorphic Adenoma & Pleomorphic Adenoma \\
\hline 21 & 24 & Female & Left & Pleomorphic Adenoma & Pleomorphic Adenoma \\
\hline 22 & 28 & Female & Right & Pleomorphic Adenoma & Pleomorphic Adenoma \\
\hline 23 & 30 & Female & Right & Pleomorphic Adenoma & Pleomorphic Adenoma \\
\hline 24 & 32 & Male & Right & Pleomorphic Adenoma & Pleomorphic Adenoma \\
\hline 25 & 32 & Female & Right & Pleomorphic Adenoma & Pleomorphic Adenoma \\
\hline 26 & 32 & Female & Right & Pleomorphic Adenoma & Pleomorphic Adenoma \\
\hline 27 & 35 & Male & Left & Pleomorphic Adenoma & Pleomorphic Adenoma \\
\hline 28 & 35 & Female & Right & Pleomorphic Adenoma & Pleomorphic Adenoma \\
\hline 29 & 35 & Female & Right & Pleomorphic Adenoma & Pleomorphic Adenoma \\
\hline 30 & 37 & Male & Left & Pleomorphic Adenoma & Pleomorphic Adenoma \\
\hline 31 & 42 & Female & Left & Pleomorphic Adenoma & Pleomorphic Adenoma \\
\hline 32 & 45 & Female & Left & Pleomorphic Adenoma & Pleomorphic Adenoma \\
\hline 33 & 45 & Female & Right & Pleomorphic Adenoma & Pleomorphic Adenoma \\
\hline 34 & 46 & Female & Left & Pleomorphic Adenoma & Pleomorphic Adenoma \\
\hline 35 & 52 & Male & Left & Pleomorphic Adenoma & Pleomorphic Adenoma \\
\hline 36 & 60 & Male & Right & Pleomorphic Adenoma & Pleomorphic Adenoma \\
\hline 37 & 45 & Female & Left & Warthin Tumor & Pleomorphic Adenoma \\
\hline 38 & 47 & Female & Right & Reactive Lymphadenitis & Reactive Lymphadenitis \\
\hline 39 & 45 & Female & Left & Sialedenosis & Sialedenosis \\
\hline 40 & 1 & Male & Right & Hemangioma & Hemangioma \\
\hline 41 & 54 & Female & Right & Pleomorphic Adenoma & Warthin Tumor \\
\hline
\end{tabular}

Table I: Age, gender, laterality, ultrasound findings and pathological diagnosis of parotid lesions 
ratio of 1.4:1. Bilateral lesions were noted in only one case (2.4\%).The most common pathology was pleomorphic adenoma which constituted 19 of the 41 cases $(46.3 \%$ of the total cases). Mucoepidermoid carcinoma constituted $7.3 \%$ of total cases. Ultrasound was able to confidently diagnose benign parotid pathologies in 36 cases (87.8\%). 2 cases which were labeled as benign on ultrasound were malignant on pathology. Sensitivity, specificity, accuracy are tabulated in table II.

\begin{tabular}{|c|c|c|c|c|}
\hline & & \multicolumn{2}{|c|}{ Pathological Diagnosis } & \\
\hline & & Benign & Malignant & \\
\hline \multirow{2}{*}{$\begin{array}{l}\text { Ultrasound } \\
\text { findings }\end{array}$} & Benign & 36 & 2 & Total=41 \\
\hline & Malignant & 1 & 2 & cases \\
\hline \multicolumn{5}{|c|}{$\begin{array}{l}\text { Sensitivity } 97.3 \% \text {, Specificity 50.0\%, PPV (94.74\%), } \\
\text { NPV } 66.67 \% \text {, Accuracy } 92.68 \% \text { (at 95\% Confidence interval) }\end{array}$} \\
\hline
\end{tabular}

Table II: Demonstrating the sensitivity, specificity of ultrasound in characterizing benign and malignant parotid pathologies

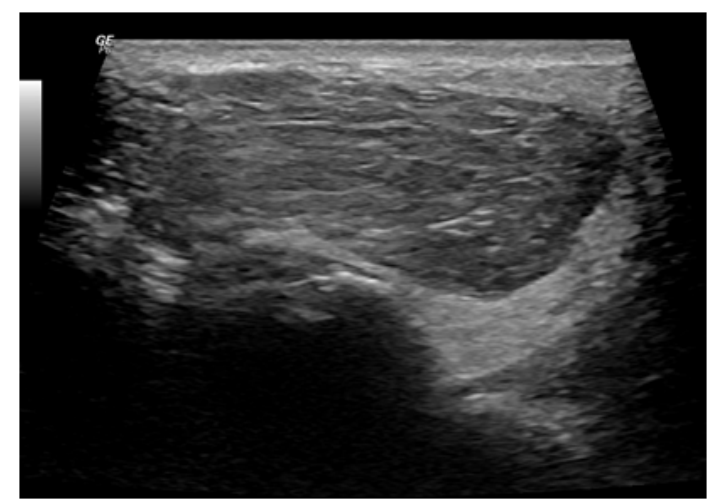

Figure 1: Ultrasound scan of the left parotid in a 19 year old male with left parotid swelling shows a well-

definedhypoechoic lesion with multiple echogenic striations which was considered diagnosed as lipoma and confirmed on cytology.

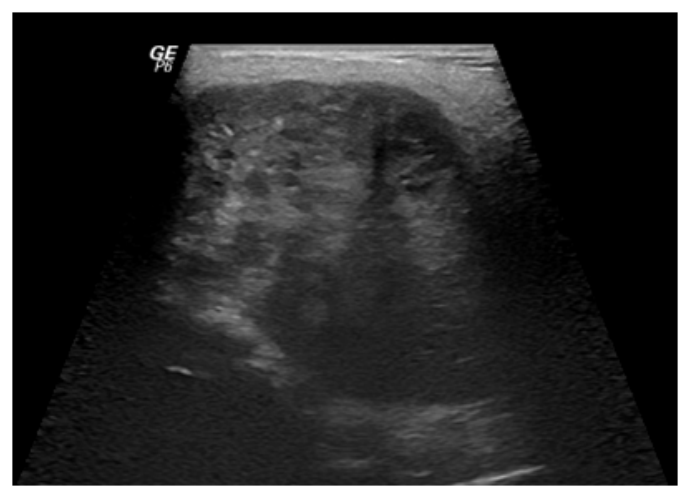

Figure 2: Ultrasound scan of the right parotid gland on a 36 year old female, shows a heterogeneous lesion with few cystic spaces which was considered pleomorphic adenoma but proved mucoepidermoid carcinoma on pathology.

\section{DISCUSSION}

Salivary gland pathologies are commonly encountered clinical problems in the Oto-rhinolaryngology ${ }^{1}$.Clinical discretion of benign and malignant pathologies is often a clinical challenge. High frequency ultrasound has proved to have a pivotal role in the evaluation of neck lesions including parotid glands ${ }^{2}$. Ultrasound is a simple, inexpensive and widely available imaging tool for the evaluation of parotid lesions and many studies have described grayscale and Doppler criteria's that help in characterizing lesions into benign and malignant with confidence ${ }^{1,3,4}$. Recently, sonoelastography and acoustic radiation force impulse imaging have further increased the diagnostic value ${ }^{5}$.

In our study, majority of the cases were noted in the 30-40 age groups which is in keeping with previous studies ${ }^{6}$. Sensitivity and specificity of ultrasound in characterizing lesions into benign and malignant was $97.3 \%$ and $50 \%$. Studies by Wu et al have demonstrated a sensitivity and specificity of $38.9 \%$ and $90.1 \%$ which is different to our study. The accuracy to differentiate benign and malignant pathologies was $96 \%$ in a study by Bialek et al whereas in our study was $92.68 \%$.

Certain studies have demonstrated inflammatory conditions as the most common parotid gland pathology ${ }^{8}$. In our study, acute, chronic and acute on chronic sialedenitis were encountered in only 5 cases. A major cause of this difference could be related to the fact that those entities usually subsides with initial treatment thus a reluctance from the treating doctors for ultrasound.

Pleomorphic adenoma is the most common benign parotid pathology. In our study, 19 of the total cases (46.3\%) were diagnosed as pleomorphic adenoma. Certain studies have demonstrated pleomorphic adenomas constituting $45.7 \%$ of all tumors which is in keeping with our study. ${ }^{9}$ Pleomorphic adenoma are typically hypoechoic, well defined, lobulated contour are certain definite ultrasound characteristics. In our study, pleomorphic adenomas were correctly diagnosed on ultrasound. Certain features such as intratumoral necrosis within pleomorphic adenoma poses diagnostic challenges ${ }^{10}$. Pleomorphic adenomas were wrongly diagnosed as Warthin's tumor in one case and as acinic cell carcinoma in another case.

Warthin's tumor is considered as second most common benign tumor compromising $4-10 \%$ of all parotid tumors was seen in only one case in our study. This difference could be related to geographic variations as in other previous studies ${ }^{11}$.

Mucoepidermoid carcinoma is the most common carcinoma of the parotid gland. Radiological findings of mucoepidermoid carcinoma are not specific and can mimic benign mixed tumors. Although, malignant tumors are usually irregular in shape, and heterogeneous in echogenicity with increased 
vascularity; mucoepidermoid carcinoma can behypoechoic and well defined on ultrasound. Cystic changes in pleomorphic adenomas can pose diagnostic dilemma as in various study ${ }^{12}$. In our study, two cases considered as pleomorphic adenomas with cystic changes on ultrasound were later confirmed as mucoepidermoid carcinoma on pathology.

Parotid lipoma is a rare pathology encountered on ultrasound for parotid masses. In our study, we found only one case of parotid lipoma which was seen as a hypoechoic lesion with multiple linear striations. Although, small sample size is one of the limit of our study; this study still depicts the relative frequency of the various pathologies, ultrasound characterization of lesions which helps in orderly management of cases avoiding unnecessary interventions that increases morbidity.

\section{REFERENCE}

1. Bruneton JN, Mourou MY. Ultrasound in salivary gland disease. ORL J Otorhinolaryngol Relat Spec. 1993;55(5):284-9.

2. Sodhi KS, Bartlett M, Prabhu NK. Role of high resolution ultrasound in parotid lesions in children. Int J Pediatr Otorhinolaryngol. 2011;75(11):1353-8.

3. Wu S, Liu G, Chen R, Guan Y. Role of ultrasound in the assessment of benignity and malignancy of parotid masses. Dentomaxillofac Radiol. 2012;41(2):131-5.

4. Carotti M, Ciapetti A, Jousse-Joulin S, Salaffi F. Ultrasonography of the salivary glands: the role of grey-scale and colour/power Doppler. Clin Exp Rheumatol. 2014;32(1 Suppl 80):S61-70.

5. Mansour N, Stock KF, Chaker A, Bas M, Knopf A. Evaluation of parotid gland lesions with standard ultrasound, color duplex sonography, sonoelastography, and acoustic radiation force impulse imaging - a pilot study. Ultraschall Med. 2012;33(3):2838.

6. Patange NA, Phatak SV. Ultrasound and Doppler evaluation of salivary gland pathology. International Journal of Research in Medical Sciences. 2016;5(1):79-82.

7. Bialek EJ, Jakubowski W, Karpinska G. Role of ultrasonography in diagnosis and differentiation of pleomorphic adenomas: work in progress. Arch Otolaryngol Head Neck Surg. 2003;129(9):929-33.

8. Madani G, Beale T. Inflammatory conditions of the salivary glands. Semin Ultrasound CT MR. 2006;27(6):440-51.

9. Dumitriu D, Dudea SM, Botar-Jid C, Baciut G. Ultrasonographic and sonoelastographic features of pleomorphic adenomas of the salivary glands. Med Ultrason. 2010;12(3):175-83.

10. Bialek EJ, Jakubowski W. Mistakes in ultrasound examination of salivary glands. J Ultrason. 2016;16(65):191-203.

11. Lawal AO, Adisa AO, Kolude B, Adeyemi BF, Olajide MA. A review of 413 salivary gland tumours in the head and neck region. J Clin Exp Dent. 2013;5(5):e218-22.

12. Khetrapal S, Jetley S, Hassan MJ, Jairajpuri Z. Cystic Change in Pleomorphic Adenoma: A Rare Finding and a Diagnostic Dilemma. J Clin Diagn Res. 2015;9(11):ED07-8. 